\title{
Gender discrimination and regulatory behaviour: an exploratory study in policing
}

\author{
Tim Prenzler \\ School of Criminology and Criminal Justice, Griffith University, Brisbane, Queensland, \\ 4111, Australia. Tel/Fax: (011-61) (0)7 3875 5613/5608; email: t.prenzler@griffith.edu.au \\ Received: 12 November 2003; accepted 7 January 2004
}

Tim Prenzler is head of the School of Criminology and Criminal Justice, Griffith University. His research interests include civilian oversight of police, the history of women police, and the development and regulation of the security industry.

\section{Abstract \\ This paper examines the relationship between police departments and equity agencies in Aus- tralia. Previous research has shown marked dif- ferences in the performance of police in fulfilling the requirements of equity legislation. Responsi- bility for ensuring compliance with anti- discrimination and affirmative action legislation rests with equity agencies - which 'police the police'. The paper reports the results from a survey of these agencies to obtain their accounts of factors facilitating or hindering police compliance. These factors are framed in terms of agency powers, resources, regulatory strategies and police responses. The study found that regulatory agen- cies were highly detached from police departments and that differences in compliance were largely the result of factors independent of regulatory action. $A$ 'culture of under-enforcement' remained as the most likely explanation for regulatory failure. The paper concludes by emphasising the need for more active monitoring and a more confrontational approach to under-achieving departments.}

\section{BACKGROUND}

This study was developed in response to research showing major differences between police departments in Australia in the 1990s in the application of legislated antidiscrimination and equal employment opportunity principles. A study by Prenzler and Hayes (2000) found a highly mixed picture of the degree of commitment and achievement in gender equity on the part of the eight departments. Performance was measured across indicators such as male and female application, recruitment and academy graduation rates; deployment, promotion, and retention rates; and complaints of harassment or discrimination. Attention was also given to the extent to which departments collected data to measure performance and engage in diagnostic assessments of problem areas. The findings showed a fairly consistent pattern in outcomes, with three main levels of performance. New South Wales (NSW) and Queensland stood out as high achievers in employing and promoting women police - with recruitment of women up to 33 per cent and above, and affirmative action support programmes in place. Tasmania, South Australia (SA), the Northern Territory (NT) and the Australian Federal Police (AFP) showed moderate achievement. Victoria and Western Australia (WA) were notable for lack of progress in advancing women police. All departments had inadequate data collection processes; although NSW, in particular, and Queensland had the best. Departments in the middle group were generally good performers in recruitment and training -
International Journal of Police Science and Management, Vol. 6 No. 3, 2004, pp. 171-182. (C) Vathek Publishing, 1461-3557 
recruiting and graduating about the same number of women as applied - but this was representative of a largely passive approach to equity management with very limited affirmative action for most of the 1990s. The third group clearly discriminated in recruitment, especially through the use of difficult obstacle course tests, and had low percentages of women police officers. Overall, there was a somewhat bleak picture, with women only 15 per cent of police across Australia in 1998, very small increases in numbers, and very few women in senior management (2 per cent in 1998). There was also higher attrition of women, lack of family friendly policies, and indicators of ongoing problems of sexual harassment and discrimination.

The study by Prenzler and Hayes (2000) and other research covering the 1990s (FCLCV, 1999; Niland, 1996; Prenzler, 1998; Tynan, 1995) indicated that performance differences were closely related to differences in internal management policies, especially at the very top of the police organisation. There appeared to be some limiting external factors, such as the percentage of women that could be attracted to apply to join the police; and some external driving factors, such as corruption inquiry reform agendas. However, performance across most indicators could be, and was, improved by changed management strategies. What was unclear, however, was the extent to which equity agencies and legislation influenced management commitment. The current study was therefore designed to examine how government equity agencies - charged with facilitating and enforcing compliance with equity legislation - interacted with police departments. Issues included the extent to which agencies had sufficient legal power to direct police to take certain action or sufficient resources to properly assess departmental performance. There was also a question about the extent to which police departments were able to evade reporting requirements or directions from equity agencies.

The development of equity regulation in Australia has typically involved a two-stage process on a piecemeal jurisdictional basis from the 1970s. Initially, legislation prohibiting sex discrimination was introduced that is common to all sectors of society. This legislation is essentially passive because it simply requires non-discrimination but does not require active measures to improve equality. An occupational area may be largely free of discrimination but have very few women in total, and few women in management or specialist positions, because of lack of applications from women (Thornton, 1990, 2001). As a result of this experience, a second generation of legislation was introduced that required active measures to encourage equity. Deference to the private sector meant that this legislation was focused on government departments, with private enterprise largely exempt. (The federal Equal Opportunity for Women in the Workplace Act 1999 now places reporting requirements on companies with over 100 employees.) Affirmative action legislation has been applied progressively to all federal and state agencies. It usually comes under the innocuous title of 'equal opportunity' legislation. However, it entails 'affirmative action' in the sense that special measures (or a degree of 'preferential treatment') are required to increase equity for women (and other target groups). This includes a requirement to submit annual plans on strategies to encourage women, and to report and evaluate progress. Specific strategies can include targeted recruitment advertising, career planning workshops, women's advisory committees, workplace childcare, prizes and scholarships, reserved places on selection committees for women, and rejoining campaigns. Reports are assessed by the independent equity agency, which is charged with taking action to remedy deficiencies. 
The study of how equity legislation is enforced falls within the discipline of regulatory studies. The uneven performance and marked equity deficits within Australian policing in the 1990s are indicative of 'regulatory failure'. From the point of view of failure, the most likely causal factors associated with the activities of regulatory agencies can be listed as follows:

1. inadequate powers;

2. inadequate resources;

3. political interference;

4. capture (undue influence of the regulator by the regulatee);

5. a culture of under-enforcement.

Research in Australia has identified underenforcement as a major historical feature of regulatory behaviour (eg Ayres \& Braithwaite, 1996; Grabosky \& Braithwaite, 1985). Inadequate powers and resources have been cited as contributory factors, but the research has highlighted a culture of deference on the part of regulators towards the powerful private and public sector bodies whose behaviour is the target of regulation. The reasons for a deferential culture have at times been related to forms of capture by influence: the interchange of personnel between the regulatee and regulator (Grabosky \& Braithwaite, 1985), for example, and to mutuality derived from working in a common field (Goldsmith, 1996). Weak and detached regulation contrasts with modern concepts of 'smart regulation' and 'responsive regulation' (Ayres \& Braithwaite, 1995; Gunningham \& Grabosky, 1998; Sparrow, 2000). Successful regulation entails the use of a broad mix of strategies targeted at specific causes of noncompliance, along with the necessity of a 'get tough' commitment by regulators. Key strategies include advice to aid compliance, prosecution of serious and repeat offenders, publicising prosecutions to deter offending, proactive auditing of compliance, the application of inquisitorial powers (to obtain evidence), the use of warning notices and directives, negotiating compliance agreements, and complaints profiling to identify patterns and trends in possible misconduct. These are the sorts of strategies that should have been available to regulators of equity in policing.

\section{METHOD}

A two-part research method was devised to explore how equity outcomes in policing may have been affected by different approaches to regulation. Both parts of the study framed police performance in the 1990s with reference to the three categories described above:

$\begin{array}{ll}\text { High achievers } & \text { NSW, Queensland } \\ \text { Moderate achievers } & \text { Tasmania, SA, NT, } \\ & \text { AFP } \\ \text { Recalcitrants } & \text { Victoria, WA. }\end{array}$

Part I of the project involved an assessment of the nature of each jurisdiction's equity legislation and the time of its introduction. This would provide indicators of the adequacy and possible impact of legislation. Relevant legislation was identified by internet searches in government websites and the electronic legal search engine AustLII (Australian Legal Information Institute). Part 2 utilised a survey of equity agencies to obtain their views on their powers and resources, and on the extent to which police departments cooperated or defied the agency.

The survey involved sending a letter to the director of each of the eight agencies responsible for regulating police. The mailout was conducted in October 2001. A copy of the main study described above (Prenzler \& Hayes, 2000) was attached to provide the national context for police department performance. Respondents were asked to describe the police in their jurisdiction in regard to Equal Employment Opportunity (EEO) performance and 
interactions in the 1990s. The following dimensions were suggested:

1. largely self-determining and complied with equity principles with little assistance or direction from the equity agency;

2. compliant but only in response to pressure from the equity agency;

3. largely self-determining and either noncompliant or under-performed, and the equity agency was unable to devote attention to the problem; and

4. largely self-determining, and either noncompliant or under-performed by resisting pressure from the equity agency.

Respondents were then asked to identify how the legal powers and resources of their agency facilitated or impeded its capacity to oversee the police department and obtain compliance. In addition, respondents were asked to elaborate on their responses, citing examples of conflict or cooperation, or of significant change, and any other factors such as political interventions or legal cases - which affected equity strategies in the police in their jurisdiction.

\section{RESULTS}

\section{Part 1: The legal context}

Table 1 sets out the results of the legislation search with dates in which equity legislation was introduced in each jurisdiction. The results confirm a two-stage process, with initial broad anti-discrimination legislation followed by affirmative action legislation requiring more active measures in the public sector. In some cases, the latter legislation has 'affirmative action' or 'equal opportunity' in the title. In the case of the NT, affirmative action is part of public sector management legislation - a type of legislation that applies in most other jurisdictions and provides another layer of authority for action on equity. The results do not show any consistent correlations between the introduction of legislation and the three categories of performance of the eight police departments - although the time of introduction of legislation may have influenced performance in some cases. The high achievers - NSW and Queensland had affirmative action legislation in place

\section{Table 1: Primary Australian equity legislation}

High achievers

NSW AD Anti-Discrimination Act 1977

AA Anti-Discrimination Act 1977 (amended 1980)

Qld AD Anti-Discrimination Act 1991

AA Equal Opportunity in Public

Employment Act 1992

Moderate achievers

Tas. AD Anti-Discrimination Act 1994

AA? State Service Act 2000^ (not applicable to sworn officers)

SA AD Sex Discrimination Act 1975

AA Equal Opportunity Act 1984

NT AD Anti-Discrimination Act 1996

AA Public Sector Employment and Management Act 1998

AFP AD Sex Discrimination Act 1984 (not applicable to sworn officers)

AA Affirmative Action Act 1986 (not applicable to sworn officers)

Recalcitrants

Vic. AD Equal Opportunity Act 1984 (amended 1995).

AA Public Authorities (Equal Employment Opportunity) Act 1990

WA AD Equal Opportunity Act 1984

AA Equal Opportunity Act 1984 (Part IX, EO in Public Employment)

Notes:

$\mathrm{AD}=$ anti-discrimination; $\mathrm{AA}=$ affirmative action. ${ }^{\star}$ The Act is not explicitly an affirmative action Act but it authorises the Anti-Discrimination Commissioner to give directives. A 2002 Directive, Workplace Diversity, includes requirements for active measures to encourage the public employment of under-represented groups, and includes standard requirements of planning and monitoring. 
either before the 1990s or early in the period. But the 'recalcitrants' - Victoria and WA - were also subject to both forms of legislation across the 1990s with no substantive effect. In the case of the moderate achievers - Tasmania, SA, NT and the AFP - there was a mixed picture. Tasmania had anti-discrimination legislation in place by the late 1990s but more demanding public sector equity standards only came into force at the very end of the period and did not cover police officers. South Australia had both types of legislation in place before the period, whereas the NT obtained the legislation only in the second half. The Commonwealth of Australia had both types in place before the 1990s but the AFP was not subject to these requirements in regard to sworn officers and was essentially under Ministerial oversight on equity (see Part 2). This situation changed with the Public Service Act 1999, although it appears that oversight remains confined to the Minister.

A content analysis of the legislation supported the existence of the model outlined above, with some variance, in which police departments are required to submit equity plans and reports to equity agencies. Plans should include measures to encourage women in recruitment, deployment and promotion. Regulatory agencies evaluate reports; and they have powers to criticise reports and plans, and to recommend changes. Usually agencies can also give directions, which can be enforced through a tribunal if necessary. Agencies can also undertake inquisitorial investigations or refer matters to a tribunal. Fines can be applied for non-compliance. Agency directors can also recommend the Minister give directions or censure police departments. In the period under review, the large majority of police departments were subject to this regime, at least in the latter period. An exception was the AFP, which was subject to Ministerial oversight in regard to sworn officers, but equity principles still should have been applied (see below). The Tasmanian police were also free of explicit affirmative action legislation in the period, although the Anti-discrimination Act 1998 provides considerable scope for the AntiDiscrimination Commissioner to enquire into police department practices in order to 'promote the recognition and approval of acceptable attitudes, acts and practices relating to discrimination' (s. 6b).

\section{Part 2: Agency responses}

By October 2002 all questionnaires had been completed and returned. Several questionnaires were initially sent to the wrong agency. Table 2 below lists the final outcome of the search for the agencies responsible for administering the relevant legislation to each police department. Note that in some cases equity is part of the broader portfolio of a public sector management commission. The AFP represents a peculiar situation. Background research resulted in a questionnaire being sent to the federal Sex Discrimination Commissioner within the Human Rights and Equal Opportunity Commission. However, the Sex Discrimination Commissioner disavowed jurisdiction and referred the researcher to the Minister responsible for the AFP, the Minister for Justice. The Minister referred the questionnaire to the AFP. The Director, People Strategies, at the AFP completed the questionnaire. The respondent noted that:

Just prior to the period you are interested in, the then Public Service Act 1922, specifically section $22 \mathrm{~B}$, was amended to require the AFP to develop, implement, monitor and review an effective EEO program. In particular, Public Service regulation 70AC applied the provision to sworn (police) members of the AFP, and required that an EEO program be developed on their behalf. Before this, the 


\section{Table 2: Equity regulatory agencies}

$\begin{array}{ll}\text { NSW } & \begin{array}{l}\text { Office of the Director of Equal } \\ \text { Opportunity in Public Employment }\end{array} \\ \text { Qld } & \begin{array}{l}\text { Office of the Public Service Commissioner } \\ \text { Tas. }\end{array} \\ \text { SA } & \begin{array}{l}\text { Office of the State Service Commissioner } \\ \text { Opportunity Commissioner for Equal }\end{array} \\ \text { NT } & \begin{array}{l}\text { Office of the Commissioner for Public } \\ \text { Employment }\end{array} \\ \text { AFP } & \begin{array}{l}\text { Minister for Justice } \\ \text { Vic. }\end{array} \\ \text { Equal Opportunity Commission } & \text { Office of Equal Employment Opportunity }\end{array}$

obligation to develop a program applied only to unsworn (public service) members of the then separate Office of the AFP. The programs for the period 1991-2000 included the collection and reporting of EEO statistics, and the development of more specific EEO policies.

On the question of jurisdiction, the AFP response confirmed the response of the Federal Sex Discrimination Commissioner:

No direct 'oversight' of the AFP is undertaken in relation to EEO. . other Commonwealth agencies have more monitoring functions with respect to the Commonwealth public sector in general. This is in contrast, for example, to the general oversight of the AFP priorities that occurs under Ministerial direction.

In light of this, a second attempt was made to have a representative from the Minister's office respond. This approach was also rejected. However, the AFP's response was used here in lieu of an external agency. Although, the AFP response was not from the required source, it was frank about issues of gender equality in the AFP and very useful in explaining a major change process within AFP management.

Table 3 reports responses to the integrated questions about police performance and relations between police management and the regulatory agency. The 'high achievers' and 'moderate achievers' were all designated by respondents as '(1) largely self-determining and complied with equity principles with little assistance or direction from the equity agency'. In an explanatory comment, the SA respondent did, however, indicate there had been some resistance:

- This Commission was involved in early work with the State's Police Dept. [in] 1998/99 (SAPOL)

- SAPOL then experienced internal structural problems which resulted in a sporadic approach to internal training (equity) issues

- Our relationship has significantly improved during the past twelve months; with joint training and feedback provided to SAPOL's Equity and Diversity Unit, Managers and new police recruits (SA).

The 'recalcitrants' were designated as being in transition late in the 1990s. Victoria was said to have moved from '(3) largely selfdetermining and either non-compliant or under-performed, and the equity agency was unable to devote attention to the problem' to '(2) compliant but only in response to pressure from the equity agency', and in transition from (2) to (1) at the very end of the period. Western Australia was seen as having moved from '(4) largely selfdetermining, and either non-compliant or under-performed by resisting pressure from the equity agency' for almost all of the 1990 s to (2) at the very end of the period.

Respondents were asked to elaborate on their responses. In terms of the adequacy of the law and of agency powers, the Tasmanian respondent pointed out that the State Service Act 2000 was not explicitly an affirmative action Act but authorised the Anti-Discrimination Commissioner to give directives. A 2002 Directive, Workplace 
Table 3: Equity agency responses: How would you describe the police department on EEO in the 1990s?

\begin{tabular}{|c|c|c|c|c|c|c|c|c|}
\hline \multirow[b]{2}{*}{ Response } & \multicolumn{2}{|c|}{ High achievers } & \multicolumn{4}{|c|}{ Moderate achievers } & \multicolumn{2}{|c|}{ Recalcitrants } \\
\hline & $N S W$ & Qld & Tas. & $S A$ & NT & $A F P$ & Vic. & $W A$ \\
\hline $\begin{array}{l}\text { 1. Largely self-determining } \\
\text { and complaint. }\end{array}$ & $\checkmark$ & $\checkmark$ & $\checkmark$ & $\checkmark$ & $\checkmark$ & $\checkmark$ & $\checkmark \dot{1}$ & \\
\hline $\begin{array}{l}\text { 2. Compliant in response to } \\
\text { agency. }\end{array}$ & & & & & & & $\checkmark A$ & $\checkmark$ \\
\hline $\begin{array}{l}\text { 3. Largely self-determining. } \\
\text { Non-compliant or under- } \\
\text { performed. Agency } \\
\text { unable to devote } \\
\text { attention. }\end{array}$ & & & & & & & $\checkmark$ & \\
\hline $\begin{array}{l}\text { 4. Largely self-determining. } \\
\text { Non-compliant or under- } \\
\text { performed. Resisted } \\
\text { agency. }\end{array}$ & & & & & & & & $\checkmark$ \\
\hline
\end{tabular}

Notes:

$\longrightarrow$ has moved; --- $\longrightarrow$ is moving.

Diversity, included requirements for active measures to encourage the public employment of under-represented groups. However, police are not covered by this Act. The SA respondent noted that, 'CEOs' performance [was] not linked to EOMP outcomes'. The WA respondent pointed out that the Equal Opportunity Commissioner had no direct authority over police but could only refer matters to the Equal Opportunity Tribunal. The Victorian respondent commented that, 'Enforcement and intervention powers of anti-discrimination bodies require significant enhancement, however this has not been a particular impediment to working with police'. The respondent from NSW noted that 'Case law. . .assisted'. (This may have been in reference to successful civil actions by aggrieved women against the NSW Police in the early 1980s.)

Only two respondents explicitly identified under-resourcing as a problem. The respondent for the SA Commissioner for Equal Opportunity indicated that the
Commission had insufficient trainers to send to departments. The WA respondent made reference to being limited by a 'small team of 10 [full time equivalent]' with ' 300 agencies [that] report to this office and require advice and assistance; comprising 152 public sector, 144 local government authorities and 4 universities':

With such limited resourcing the planning and reporting requirements are fairly standardised across all public authorities. This allows for the development of comparable measures for benchmarking purposes, but limits the degree of customised service.

In terms of regulatory strategies, most respondents noted that they received EEO reports and plans, and that they engaged in benchmarking departmental performance and providing advice to improve compliance. This is evidenced in the following examples: 
Our Commission calls upon the following resources to assist SAPOL: 1. Training and Education Officers, 2/ Legal Practitioners and 3/ General Enquiry Service (SA).

The work between this Commission and the Police has relied more on good will than legal authority. In terms of practical strategies the Commission has relied on its mandate to educate (s.162 EOA), and no doubt the possibility of complaints has in part been a motivator for Police. .. The Commission's considerable experience and expertise in the area of training has positioned it well to respond to the needs of Police re. proactive equity strategies (Victoria).

In terms of specific events or issues, the following comments were provided. The AFP respondent reported on a 'watershed' change that followed from events in the mid 1990s. Complaints of sexual harassment against both male and female officers and non-sworn members provoked a major internal investigation that was conducted with assistance from the Human Rights and Equal Opportunity Commission. The gravity of the long-term harassment revealed by the investigation led to the AFP engaging an external consultant to conduct an 'Equity Performance and Cultural Assessment'. The resulting Niland Report (Niland, 1996) identified a problem with a sexist culture and was used to underwrite the AFP's intention to embark on positive culture change with respect to EEO'.

The Victorian response attributed change to two significant events. The first was the Narelle McKenna case, which was finalised in 1999. The State Anti-Discrimination Tribunal awarded McKenna \$125,000 damages following revelations of intense discrimination and harassment. The Police Department's loss prompted a review of equity policy that acknowledged the need for more support for EEO target groups. The second event was the appointment of a new Chief Commissioner (Christine Nixon in 2000), which was deemed 'invaluable'. The WA respondent emphasised senior police resistance to agency efforts to stimulate compliance. The Office of Equal Employment Opportunity conducted an EEO and Diversity Review of the WA Police in 1998, which revealed that the service was well below national averages in gender equity, including having the lowest percentage of female police, and the lowest percentage of female commissioned officers. An opinion survey also showed a problem with sexual harassment of female staff and lack of staff confidence in equity management. These findings were presented to Commissioner Falconer, along with a recommended improvement strategy. Although the Commissioner made a commitment to implement substantial change. . this didn't occur. . .It has proved very difficult to form a strategic working partnership with Police, particularly the HR division'. The change indicated in Table 3 was explained by the appointment of a new commissioner:

Up until 2000 there was considerable resistance from the WA Police to undertaking proactive measures to achieve EEO and diversity. The compliance was at the minimal level, with a general lack of senior management commitment or focus. Significant increase in WA Police attention to gender issues in recruiting and career development, since the arrival of the new Police Commissioner, $\mathrm{Mr}$ Barry Matthews, two years ago [1999] [resulted in a] new Police Strategic Plan - focus on diversity of Police employees - [and] partnership with our office.

\section{DISCUSSION}

This research supports the view that in the 1990s equity agencies were largely on the sidelines when it came to enforcing the law 
against police departments in Australia. In at least one case, that of the WA police, this was associated with deliberate resistance by senior members of the department. But in all cases, detachment appears to have been the result of a culture of under-enforcement within the regulator. This, at least, appears as the most likely explanation in terms of factors affecting regulatory failure. The presence or absence of affirmative action legislation was important, but legal efficacy occurred primarily when police management adopted a positive attitude to compliance or when civil cases stimulated change (cf Prenzler, 1998). There were no reports of political interference (although this type of explanation would be highly unlikely to be revealed in this type of selfreport survey). There were few complaints of inadequate agency powers, and the analysis of the legislation supported this position. Only the WA respondent made a clear connection between lack of resources and the inability to regulate a department properly. (At the same time, the Victorian response to the closed-ended section of the questionnaire included reference to the agency being "unable to devote attention to the problem'.)

Statements by respondents also lent some support to a culture of under-enforcement thesis. Agencies were generally open about taking a 'softy softly' approach in restricting their regulatory actions to auditing police self-reports and offering advice. In one of the most extreme cases of non-compliance - that of the WA police - the respondent conceded that the option of taking the police department before a tribunal was not taken. In the case of the Victorian police, there was very strong evidence of a culture of intense sex discrimination right through the 1990s (FCLCV, 1993, 1999) and, despite mounting evidence, the equity agency did not exercise its powers. Victims were forced to take their complaints to the courts - an extremely hazardous and stressful course of action. The systemic problems revealed in the courts should have been identified much earlier under a proper regulatory regime. The Narelle McKenna case, and similar cases, galvanised a group of activists to form 'Operation Womenforce'. The group began a publicity campaign 'to combat the perceived institutionalised harassment, neglect and negation of women police in Victoria' (Journal, 1998, p. 11). In 1999 Commissioner Comrie, who fought the aggrieved women in the courts, was obliged to declare that the Department had not done enough to remove discrimination and launched an equity program to 'catch up with community standards' (Towers, 1999 , p. 3). There was also considerable case law and scientific evidence to show that the notorious obstacle course tests used by the WA and Victorian police were invalid as selection tools and would have been struck down by a tribunal (Prenzler, 1996).

The detachment of equity agencies can also be seen in their relationships with both the 'high achievers' and 'moderate achievers'. Regulators tended to settle for passive, apparently non-discriminatory, practices by the moderate achievers. This was despite the fact that the law, in the main, sought 'affirmative action', and that a progressive regulator would have sought more information to test compliance. Even where police departments performed well on numerous indicators, there was no apparent attempt to probe more deeply for possible hidden forms of non-compliance. This is most apparent in the Queensland case, where the introduction of a discriminatory obstacle course test in recruitment in 1994 was endorsed by the equity agency, only to be removed at a much later date following an investigation by the State's anti-corruption body (CJC, 1998).

In making few complaints about resources it is possible that some or all of the respondents to this survey overestimated 
their capacity to regulate the police. Nonetheless, most regulatory agencies are underresourced in relation to all the challenges they face, and they need to select cases to pursue in terms of both the seriousness of non-compliance and the general utility to be achieved from the example (Ayres \& Braithwaite, 1995; Sparrow, 2000). From this perspective, police departments made perfect targets. Police receive close attention from the media, so that 'naming and shaming' would have resulted in a message that was widely broadcast. Police have also been one of the most male dominated, and most independent and powerful, arms of government. Success in obtaining compliance from the police would have provided a telling example to other departments.

Overall, this research supports the case for a more active approach to equity regulation in Australia, including greater use of directives and legal action. Current equity laws and agency resources appear to be largely adequate. Enforcement is the vital issue. At the same time, this research also showed the need for police to operate on a common standard. In particular, there is no reason to see Tasmanian or Federal police officers as worthy of exemption. It would seem logical in a federal system for the Commonwealth to initiate production of a national model Act and regulatory regime, endorsed by the states and territories, that apply equally to police and other public servants.

It should be emphasised that this research does not claim to provide a definitive explanation of regulatory failure. In fact, it probably raises more questions than it answers, especially in terms of the nature and causes of the purported 'culture of underenforcement'. Research on this dimension of regulation has tended to focus on underenforcement as a product of industry capture, through corruption or layers of influence (Ayres \& Braithwaite, 1992). However, the regulation of gender equality in policing is not likely to be subject to common conditions of capture - such as personnel moving from a regulatee to work for the regulator, or regulatees having opportunities to bribe regulators. The research certainly underscores the need 'to build a regulatory culture wherein regulators are socialised to be tough on cheaters' (Ayres \& Braithwaite, 1992, p. 92). But how to do this, and the precise obstacles, appear crucial areas for further research.

\section{Postscript and conclusion}

The 1990s were marked by a clear divergence between police departments in Australia in the way they managed gender equity. At the very end of the 1990s this changed, and an alignment occurred. The principal cause of this change was the appointment of new commissioners. The change was already underway in Tasmania and the NT from 1995 as modernising commissioners responded positively to a more active EEO agenda in government (Tasmania Police, 1996, p. 142; NT Police, 1996, p. 20; NT Police News, 1996, p. 9). In the AFP, Commissioner Palmer (appointed 1994) had been an outspoken supporter of women and worked to support the Niland Commission recommendations of 1996. When Barry Matthews was appointed Police Commissioner in WA in 1999, he was quick to declare his commitment to improving the position of women and began working with the Office of Equal Employment Opportunity. In Victoria, Christine Nixon was appointed Chief Commissioner in 2000. She also set about a programme to improve the position of women. One of her first acts was to remove the high wall in the obstacle course that had served to exclude thousands of women from the Victoria Police. As indicated in the research findings above, this fresh commitment to equity has usually involved a greatly improved relationship between police management and the equity agency, 
with the agency providing advice, assistance and training. Nonetheless, the degree of substantive change remains unclear, especially in the notorious rank-and-file police culture, and policing still appears a long way from a 'family friendly workplace' (Strachan \& Jamieson, 1999, pp. 325). In addition, the source of change (new commissioners) underscores the point that equity agencies have not administered equity law from an authoritative and decisive standpoint. It must be kept in mind that police are just a few of the tens of thousands of government departments and private sector organisations subject to equity legislation. The limited wider research on equity in Australia suggests that under-enforcement is the norm (Strachan \& Burgess, 2000; Strachan \& Jamieson, 1999; Thornton, 2001). This means that the lessons from this study have wide implications for improving equity in the workplace, especially in the public sector.

In policing, the current alignment of positive leadership support for equity means that the 'big stick' approach to regulation is probably no longer needed. However, it is possible that police departments that appear to be performing well may have hidden pockets of discrimination or areas of underrepresentation of women that need to be addressed with remedial strategies. Consequently, equity agencies need to take a more probing approach to auditing than simply assessing self-reports. Recent Australian research on regulatory behaviour indicates that there is an evolution occurring away from passive regulation to smart regulation, especially in prominent agencies such as the Australian Competition and Consumer Commission and the Australian Securities and Investment Commission (ACCC, 1997; Hayes \& Prenzler, 2002; Segal, 2001). The recent catastrophic crisis over insurance industry regulatory failure (HIH Royal Commission 2003) shows this is not an automatic and universal process.
With the partial exception of the sex discrimination cases in Victoria, regulatory change in gender equity in policing has not been subject to anything like 'crisis'. Nonetheless, it is time that equity agencies obtained the resources, training and political support required to move with the times and enter into the more advanced dimension of smart regulation. This goal would be aided considerably by a coordinated national approach.

\section{References}

ACCC. (1997). The Global Enforcement Challenge: Enforcement of Consumer Protection Laws in a Global Marketplace, Discussion Paper. Canberra: Australian Competition and Consumer Commission.

Ayres, I., \& Braithwaite, J. (1992). Designing responsive regulatory institutions. The Responsive Community, Summer, 41-7.

Ayres, I., \& Braithwaite, J. (1995). Responsive Regulation: Transcending the Regulation Debate. Oxford: Oxford University Press.

CJC. (1998). Police for the Future: Review of Recruitment and Selection for the Queensland Police Service. Brisbane: Criminal Justice Commission.

FCLCV. (1993). Brute Force: The Need for Affirmative Action in the Victorian Police Force. Melbourne: Federation of Community Legal Centres Victoria.

FCLCV. (1999). Brute Force II: The Continuing Need for Affirmative Action in the Victorian Police Force. Melbourne: Federation of Community Legal Centres Victoria.

Goldsmith, A. (1996). What's wrong with complaint investigations? Dealing with difference differently in complaints against police. Criminal Justice Ethics, 15, 36-55.

Grabosky, P., \& Braithwaite, J. (1986). Of Manners Gentle: Enforcement Strategies of Australian Business Regulatory Agencies. Melbourne: Oxford University Press.

Gunningham, N., \& Grabosky, P. (1998). Smart Regulation: Designing Environmental Policy. Oxford: Oxford University Press.

Hayes, H., \& Prenzler, T. (2002). Profiling Fraudsters. Report to National Crime 
Prevention, Commonwealth AttorneyGeneral's Department. Canberra.

HIH Royal Commission (2003) Report. Retrieved August 1, 2003, from http:/ /www.hihroyalcom.gov.au/finalreport/. Journal, The. (1998). (Official Publication of the Australasian Council of Women and Policing) 1(summer).

Niland, C., (1996, July). The impact of police culture on women and their performance in policing. Paper presented at the First Australasian Women in Policing Conference, Sydney, Australia.

NT Police. (1996). Annual Report 1994-1995. Darwin: Northern Territory Police.

NT Police News. (1996). September.

Prenzler, T. (1996). Rebuilding the walls? The impact of police pre-entry physical ability tests on female applicants. Current Issues in Criminal Justice, 7(3), 314-24.

Prenzler, T. (1998). Gender integration in Australian policing: the evolution of management responsibility. International Journal of Police Science and Management, 1(3), 241-59.

Prenzler, T., \& Hayes, H. (2000). Measuring progress in gender equity in Australian policing. Current Issues in Criminal Justice, 12(1), 20-38.
Segal, J. (2001, May). Regulatory Initiatives by ASIC in the Cyber Age. Address to the Financial Markets and the Internet Conference, Faculty of Law, University of Sydney, Sydney, Australia.

Sparrow, M. (2000). The Regulatory Craft. Washington DC: Council for Excellence in Government.

Strachan, G., \& Burgess, J. (2000). W(h)ither affirmative action legislation in Australia? Journal of Interdisciplinary Gender Studies, 5(2), 46-63.

Strachan, G., \& Jamieson, S. (1999). Equal opportunity in Australia in the 1990s. New Zealand Journal of Industrial Relations, 24(3), 319-41.

Tasmania Police. (1996). Annual Report 1995-1996. Hobart: Tasmania Police.

Thornton, M. (1990). The Liberal Promise. Melbourne: Oxford University Press.

Thornton, M. (2001). EEO in a neo-liberal climate. Journal of Interdisciplinary Gender Studies, 6(1), 77-104.

Towers, K. (1999, February 5). Promise of uniform rights. The Australian, p. 3.

Tynan, M. (1995). Eighty Years of Women in Policing, New South Wales, 1915-1995. Sydney: NSW Police Service. 